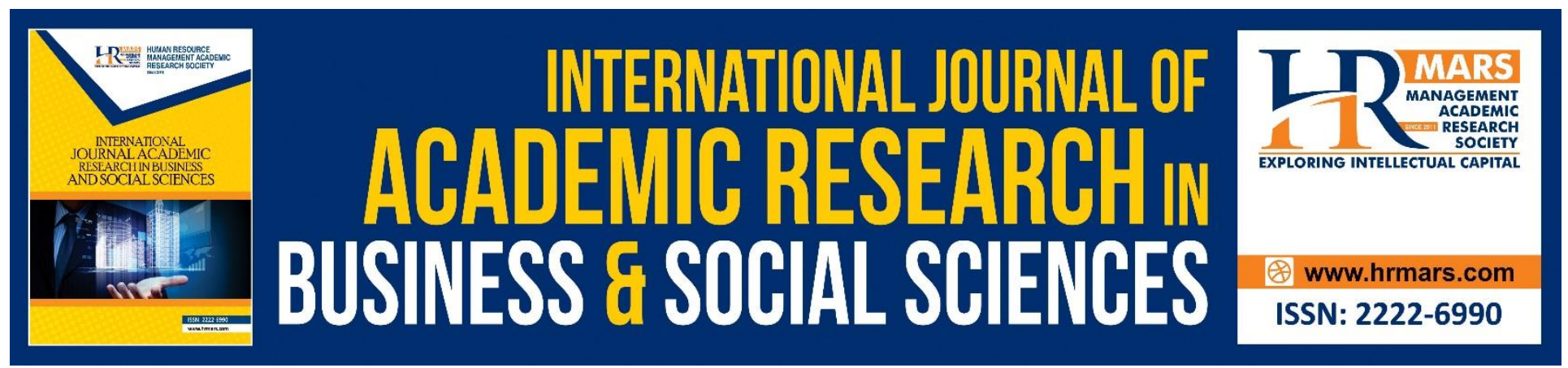

\title{
The Effectiveness of Fire and Burns at Home Education Among Primary School Children in Hulu Langat, Selangor
}

\author{
Haliza Abdul Rahman and Siti Nabila Ahmad
}

To Link this Article: http://dx.doi.org/10.6007/IJARBSS/v10-i15/8251

DOI:10.6007/IJARBSS/v10-i15/8251

Received: 11 September 2020, Revised: 14 October 2020, Accepted: 14 November 2020

Published Online: 30 November 2020

In-Text Citation: (Rahman \& Ahmad, 2020)

To Cite this Article: Rahman, H. A., \& Ahmad, S. N. (2020). The Effectiveness of Fire and Burns at Home Education Among Primary School Children in Hulu Langat, Selangor. International Journal of Academic Research in Business and Social Sciences, 10(15), 305-314.

Copyright: (C) 2020 The Author(s)

Published by Human Resource Management Academic Research Society (www.hrmars.com)

This article is published under the Creative Commons Attribution (CC BY 4.0) license. Anyone may reproduce, distribute, translate and create derivative works of this article (for both commercial and non-commercial purposes), subject to full attribution to the original publication and authors. The full terms of this license may be seen at: $\underline{\text { http://creativecommons.org/licences/by/4.0/legalcode }}$

Special Issue: Youth and Community Wellbeing: Issues, Challenges and Opportunities for Empowerment V1, 2020, Pg. 305 - 314

Full Terms \& Conditions of access and use can be found at http://hrmars.com/index.php/pages/detail/publication-ethics 


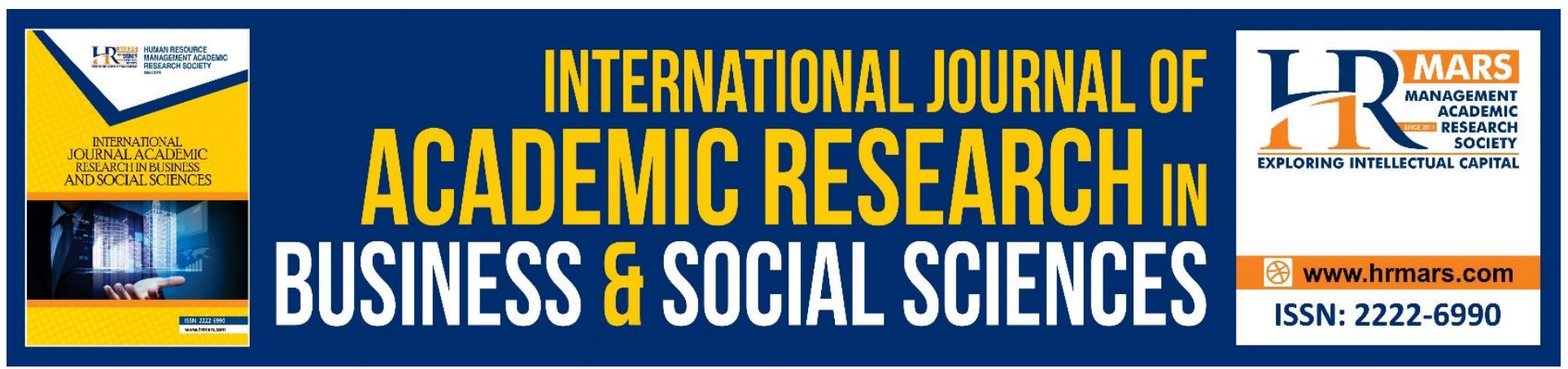

\title{
The Effectiveness of Fire and Burns at Home Education Among Primary School Children in Hulu Langat, Selangor
}

\author{
1,2 Haliza Abdul Rahman and ${ }^{2}$ Siti Nabila Ahmad \\ ${ }^{1}$ Institute for Social Science Studies, Putra Infoport, Universiti Putra Malaysia, 43400 Serdang, \\ Selangor, Malaysia, ${ }^{2}$ Department of Environmental and Occupational Health, Faculty of Medicine \\ and Health Sciences, Universiti Putra Malaysia, 43400 Serdang, Selangor, Malaysia \\ Email: dr.haliza@upm.edu.my
}

\begin{abstract}
Children are one of the highest risk groups of those who experience fire and burn related deaths and injuries at home. Compound, living room, bedroom, kitchen and stairs were the five most common locations of injuries. Objective: To study the effectiveness of fire and burns at home education among primary school children in Hulu Langat, Selangor. Method: This study uses pre-test and post-test Quasi Experimental design to evaluate the effectiveness of fire and burns at home education among primary school children in Hulu Langat, Selangor. The total number of 152 (76 x 2) students involved in this study from two primary schools. Students were divided into control and experimental groups. Experimental group was introduced with intervention learning model. Both groups were distributed with self-administered, validated and pre-tested questionnaires regarding their knowledge on fire and burns at home. Descriptive analysis was used for social-demographic distribution. As the data were normally distributed, Independent T-test was performed to compare between two unpaired groups while Paired T-test was used to compare the knowledge score before after the introduction of learning model. Data was analysed using SPSS version 21. Result: There was a significant improvement in the knowledge level among the experimental group after they participated in the educational session $(p<0.001)$. The background knowledge level between control and experimental groups were not significantly different $(p=0.97)$. However, a higher knowledge level was significantly seen in a sub-group of urban school compared to rural school ( $p<0.001$ ). Conclusion: Thus, educational and intervention program are necessary to improve the knowledge level of the children. This improvement is expected to encourage the children to mould behaviour from young ages so that safety and preventive methods become a practice.
\end{abstract}

Keywords: Fire and Burn, Home Injuries, Home Education, Intervention Learning Model, School Children. 


\section{Introduction}

Child injury is a worldwide problem. Daily, in the world the lives of more than 2000 families are torn apart by the loss of a child to accidents that are also known as unintentional injuries. Examples of unintentional injuries include road traffic, drowning, burns, falls as well as poisonings (WHO, 2008; Fernandes et.al, 2912). This study, however, focused on fire and burn at home setting because children are one of the highest groups of those who experience fire-related deaths and injury at home. Fire and burn injury is the injury to the skin or other organic tissue primarily caused by thermal or other acute trauma (Peck, 2011). The fact that home is expected to be a safer place for children, however, it witnessed scenes of numerous fire and burn injuries among them. Compound, living room, bedroom, kitchen and stairs were the five most common locations of injuries (Sahril, 2014).

In Malaysia, the report released by Safe Kids Universiti Putra Malaysia (UPM) has stated that a child dies from a fire or burn in every two weeks with $6.4 \%$ of parents reported that there were fire cases in their house in the past two years (Kulantahayan et. al, 2016). Children are one of the highest risk groups of those who experience fire and burn related deaths and injuries. This is due to the nature of their curiosity; in which they might have come into contact with objects that can cause severe injuries (Safe Kids Foundation, 2015). Children playing with fire or touching hot objects can result in fire and burn related injuries. This not only give effects in great medical costs and economic loss, but also cause immeasurable psychological consequences not only for the child, but also for wider family and community (Safe Kids Foundation, 2015).

However, fire and burn injuries are preventable (Shi et. al, 2016). Thus, this study was conducted to study effectiveness of fire and burns at home education among primary school children in Hulu Langat, Selangor. Fire and burn at home as the focus because there were less studies done compared to road and occupational injuries in Malaysia (Peck, 2011). While there were less studies related to home injuries, only $11 \%$ of parents' report that schools frequently teach fire safety education (Sahril et. al., 2014). This statistic illustrates the need for education efforts to include messages on proper prevention as fire and burns are preventable.

Selangor was chosen as the sampling location because the highest number of fire cases with bad consequences of death and injuries compared to other countries in Malaysia. Surprisingly, Selangor also recorded the highest number of fire, rescue and special service calls (17, 737 calls) in 2016 (Olanbanji et. al., 2007). Other than that, by referring to the report released by Safe Kids Malaysia, children age ten and eleven years old showed a higher percentage of getting fire and burn related injuries compared to other ages. Half of them, which was $58.6 \%$ of students age ten and $53.1 \%$ of eleven years old children had injured due to fire and burn related cases (Sahril et. al., 2014). Therefore, in this study, students from both ages were selected as study population. All manuscripts must be in English, also the table and figure texts, otherwise we cannot publish your paper.

Interventions such as Education, enforcement, and engineering (3E's) have traditionally been considered to prevent unintentional injuries. Interventions also considered in terms of preventing the occurrence of the injury, minimizing the severity of injury at the time of the injury, and minimizing 
INTERNATIONAL JOURNAL OF ACADEMIC RESEARCH IN BUSINESS AND SOCIAL SCIENCES

Vol. 10, No. 15, Youth and Community Wellbeing: Issues, Challenges and Opportunities for Empowerment V1. 2020, E-ISSN: 2222-6990 @) 2020 HRMARS

the severity of injury following the injury event (MHLG, 2016). Therefore, it is important to give education as well as enough information to children regarding fire and burns to save their life.

\section{Materials and Method}

This was a quasi-experimental study (pre-test and post-test) conducted in two randomly selected primary schools (rural and urban) in Hulu Langat, Selangor, Malaysia. For this research purposes, one of primary school from Cheras represented urban while primary school from Hulu Langat represented as rural area. This pre and post-test Quasi-Experimental study was carried out to determine the effectiveness of fire and burns at home education.

The study population for this study were primary school children (aged ten and eleven years old). These children were divided into control and experimental groups. The sample size was calculated using the formula of two groups comparison.

Inclusion criteria: Male and female students at the age of ten and eleven years old and have signed respondent's information sheet and informed consent form and whose parents have signed respondent's information sheet and guardian's/parent's consent. Exclusion criteria: Students who are unable to read.

The total number of sample size in this study were $152(76 \times 2)$ school children from two schools.

\section{Study Instrument}

Questionnaires on fire and burns at home were distributed to the children. Each respondent was required to answer twice the questionnaire before and after the knowledge transfer session with the aid of education learning model. The questionnaire was an adaptation from National Fire Protection Association (NFPA) (Norton et. al., 2006).

There were five sections, namely section A to E. Section A was socio-demographic factors, including type of school, child's age, gender, ethnicity and experience of fire and burns at home. Section B asked about the general knowledge on fire and burns. Sections C contained questions related to identify hot and cold objects. Section D was about the steps of 'Stop, Drop, and Roll' while Section $\mathrm{E}$ was steps that should be taken by the children, to minimize or preventing fire and burns incidents. The questionnaire was presented in Malay language.

The teaching model of the fire and burns at home was developed based on the teaching model as recommended by "Learn not to be burn, level 1" introduced by National Fire Protection Association (NFPA) and Fire Safety Trailer Curriculum (NFPA, 2012). The researcher shared the information regarding fire and burns by using educational tools, which was a prototype and the evaluation towards the knowledge on fire and burns among the children (using post-questionnaire) was carried out. 


\section{Study Procedures}

This study involved few steps. Step 1 was knowledge acquisition. During this process, researcher searched and collected as many information and knowledge in order to help the development of educational tool and questionnaire. After the collection of information, researcher proceeded to Step 2 which was the development of educational tool and questionnaire based on the knowledge acquired.

The process continued with Step 3 where pre-testing of both educational tool and questionnaire were carried out. The purposes of this step were as follows: 1) to test and improve the educational tool based on the response given by the school children, 2) to ensure all questions in the questionnaire provided were understandable by the school children and suitable with the educational tool being used. Next, Step 4 included the improvements of the educational tool and the questionnaire based on the comments given during the pre-testing.

Moving to Step 5 which was pre-testing to both experimental and control groups. It was conducted by distributing questionnaire to the selected students. In step 6, educational tool was given to experimental group while control group received no education related to fire and burns at home over the same period of time. Post-testing (Step 7) was conducted to both groups after one week to identify the effectiveness of educational tool in transferring information.

\section{Data Analysis}

Data analyses were conducted using SPSS version 21.0. Descriptive statistics of variables were presented as frequency, percentage, mean, median, interquartile range, and standard deviation. For comparison between two unpaired groups, Independent Sample T-test or Mann Whitney U test was conducted based on normality test findings. Again, depending on normality distribution, Paired Sample T-test or Wilcoxon signed-rank was used to compare between two paired groups (before and after the introduction of learning model). Final results were significantly difference at a level of $p$ value $<0.05$ (USFA, 2007).

\section{Ethics}

Data collection was initiated only after the Ethics Committee for research involving Human Subjects of Universiti Putra Malaysia gave permission and approval (Reference: UPM/TNCPI/RMC/1.4.18.2). Permission from Educational Planning and Research Division of Ministry of Education Malaysia and Selangor State Education Department were requested and received. All the stakeholders such as primary school teachers and parents were informed and explained in detailed about the study before parental consents were obtained prior to the questionnaire deliveries and educational session.

\section{Results}

Socio-demographic Information

This study was able to recruit 152 number of participants. More than half of them (55.9\%) were female students. Malays are the majority ethnics; $98.7 \%$, followed by Indians; $0.7 \%$, and 
another race (0.7\%). 69 (45.4\%) of the children were reported of experiencing fire and burn related injuries while $3.3 \%$ claimed that they had experienced burning home.

The results in Figure 1 showed that among students who experienced fire and burn injuries, there were higher percentages of males when compared to females. There were also higher percentages of urban compared to rural school as shown in Figure 2.

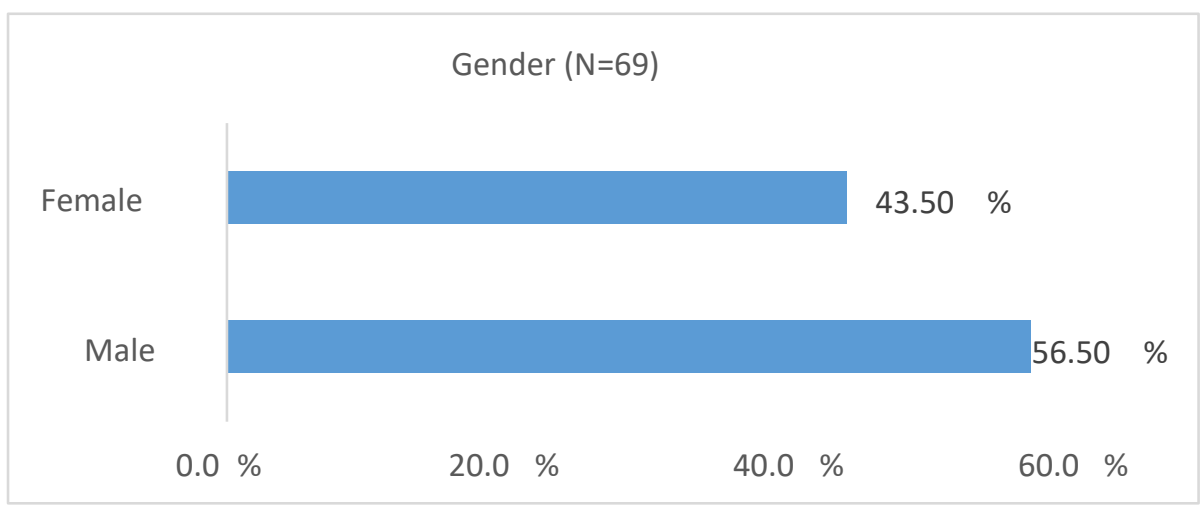

Figure 1: Percentage of fire and burn injuries across gender $(\mathrm{N}=69)$

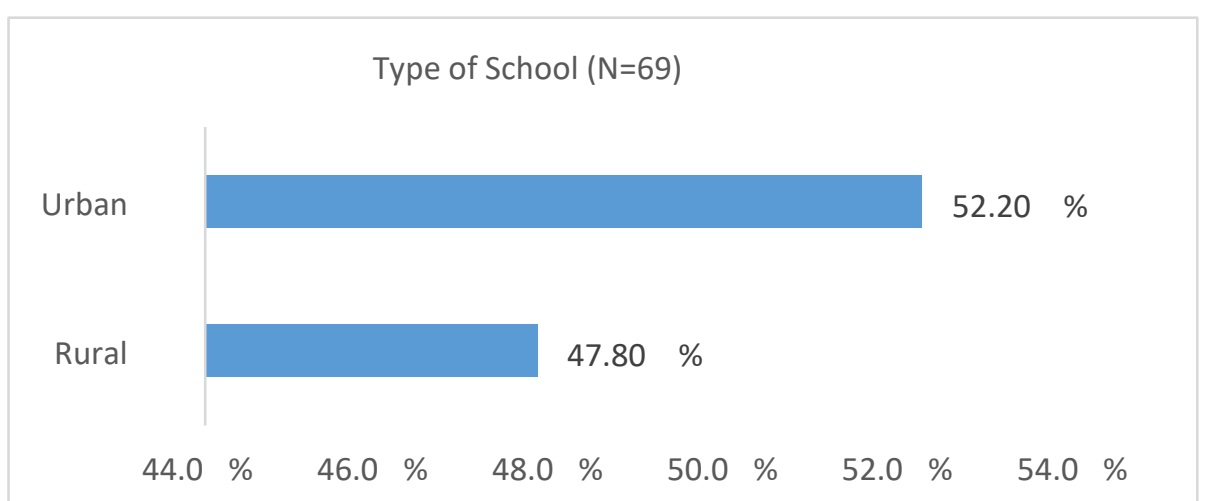

Figure 2: Percentage of fire and burn injuries across type of school $(\mathrm{N}=69)$

\section{Background knowledge between groups}

There were no significant group differences among control and experimental groups. The overall result of background knowledge of fire and burn before the introduction of learning model among control and experimental groups was tabulated in Table 1. However, there was a significant difference on the background knowledge of fire and burn at home when comparing between rural and urban schools. The result is as shown in Table 2.

Table 1: Background knowledge of fire and burn at home between control and experimental groups

\begin{tabular}{|c|c|c|c|}
\hline \multirow[t]{2}{*}{ Variables } & \multicolumn{2}{|l|}{ Mean (SD) } & \multirow[t]{2}{*}{ p-value } \\
\hline & Experimental & Control & \\
\hline Pre-Test & $\begin{array}{l}22.37 \\
(219)\end{array}$ & 22.36 & $0.97^{*}$ \\
\hline
\end{tabular}

$* p$ is significant when $<0.05$ 
Table 2: Background knowledge of fire and burn at home between rural and urban schools

* $p$ is significant when $<0.05$

\begin{tabular}{llll}
\hline Variables & \multicolumn{2}{l}{ Mean (SD) } & p-value \\
\cline { 2 - 3 } & Rural & Urban & \\
\hline Pre-Test & 20.87 & 23.86 & $<0.001^{*}$ \\
Knowledge & $(1.96)$ & $(1.87)$ & \\
\hline
\end{tabular}

Knowledge on Fire and Burn After the Introduction of Learning Model

Further analysis performed between control and experimental groups after the intervention learning model applied to the experimental group. There was a significant different between these two groups as revealed in Table 3.

Table 3: Knowledge on Fire and Burn After the Introduction of Learning Model Among Control and Experimental Groups

\begin{tabular}{lllll}
\cline { 2 - 4 } & Variables & \multicolumn{2}{c}{ Mean (SD) } & p-value \\
\cline { 2 - 4 } & & Control & Experimental & \\
\cline { 2 - 5 } & Post-Test & 22.58 & 27.37 & $<0.001^{*}$ \\
Knowledge & $(2.17)$ & $(1.57)$ & \\
\hline \multirow{2}{*}{$p$ is significant when $<0.05$} & & &
\end{tabular}

Paired T-test analysis was carried out to compare the knowledge level of fire and burns at home before and after the introduction of intervention model. This analysis was done among students in experimental group. Referring to Table 4, there was a significant improvement on the knowledge level after the students joined the educational session.

Table 4: Knowledge on Fire and Burn among experimental group before and after the introduction of learning model

\begin{tabular}{lllll}
\hline Variables & \multicolumn{3}{c}{ Mean (SD) } & \multirow{2}{*}{ p-value } \\
\cline { 2 - 5 } & & Before & After & \\
\cline { 2 - 5 } Post-Test & 22.36 & 27.37 & $<0.001^{*}$ \\
Knowledge & $(2.66)$ & $(1.57)$ & \\
\hline
\end{tabular}

$* p$ is significant when $<0.05$

\section{Discussion}

Socio-demographic information

In this study, female participants, (56.5\%) in rural and (55.3\%) in urban areas showed predominance in comparison to male participants. Hemeda et. al also found similar data in their study (Ghasemi \& Zaheiasl, 2012). In this study, the two schools selected consisted of higher female students compared to male students in total.

Most of the students participated in this study were Malay. In rural area, all of the school children $(100 \%)$ and majority of children in urban area (97.4\%) were Malays. This was because both schools 
INTERNATIONAL JOURNAL OF ACADEMIC RESEARCH IN BUSINESS AND SOCIAL SCIENCES

Vol. 10, No. 15, Youth and Community Wellbeing: Issues, Challenges and Opportunities for Empowerment V1. 2020, E-ISSN: $2222-6990$ ๑ 2020 HRMARS

selected were Malay-stream school systems. Most of the students in Malay-stream schools consist of Malay ethnic, with minorities of other races.

Based on the reported fire and burn injuries, males had a higher tendency (56.5\%) to get involved with the injuries compared to female (43.5\%). This result is supported with previous study, in which they stated that male children are at increased risk, often due to fire play and risk-taking behaviours (Hemeda, Maher \& Mabrouk, 2003). The study also stated that males are more impulsive and destructive than females. It is encouraging to compare this statement with that found by in the previous study by Sahril et. al (2014) stated that the difference between genders may be related to traditional males and females' roles (Peck, 2011). Differences in socialisation operating at early age may also result in differences in risk-taking behaviours between males and females.

Among students who had experienced fire and burns incidents at home $(N=69), 47.8 \%$ of them were students from rural school. Surprisingly, students from urban area reported to have a higher percentage (52.2\%) of fire and burn related injuries at home. Consistent with the literature, urban environments were also well-documented risk factors for fire and burns at home setting (Blom et. al., 2016). Other than that, researcher from previous study also found that participants from urban area had the highest incidence rate of fire and burn injuries compared to that in rural area (Parker et. al., 2013). The high incidence in children in urban areas could reflect the vulnerability among children living in cramped housing conditions (Van der Geer et. al., 2000).

From Table 4, it can be concluded that burn injuries (45.4\%) affected the children more than fire injuries (3.3\%) at home setting. This result support evidence from previous observations from previous study, who revealed that the occurrence of burn injuries among children was higher than the percentage of flame injuries (Safe Kids Foundation, 2015). Similar results were seen a study done by Chien et al. that showed predominance of burn injuries over flame injuries (Shrestha, 2006).

\section{Background Knowledge between Groups}

Quasi-experiments are subject to concerns regarding internal validity, because the experimental and control groups may not be comparable at baseline. Therefore, random assignment was used. In this study, continuous variable of knowledge score was tested for its association with the background knowledge between control and experimental groups using Independent T-test as all data was normally distributed. The difference of knowledge between those who were in control group and those who were in experimental group was statistically not significant $(p=0.97)$. This was because random assignment was used in which study participants have the same chance of being assigned to the experimental group or the control group (Chien et. al., 2003).

However, by comparing the background knowledge between students in rural and urban school, it showed a statistically significant result with value of $p<0.01$. Students in urban school had a higher mean score (23.86) compared to those in urban school (20.87). In accordance with present results, previous studies have demonstrated that there were more fire and burn victims reported in hospital came from urban area due to the fact that they had a higher knowledge level and awareness to get better treatment (Ghasemi \& Zahediasl, 2012). 


\section{Knowledge on Fire and Burn After the Introduction of Learning Model}

After the introduction of the intervention learning model, the knowledge score (post-test) on fire and burns at home were then compared between both control and experimental groups. There was a significant difference $(p<0.001)$ between control and experimental groups after the experimental group participated in the educational session. Students in experimental group had a higher mean score (27.37) compared to that in control group (22.58).

As the data was normally distributed, Paired T-test was used to compare the knowledge score of fire and burns at home (before-after) among students in experimental group. The $p$-value of this test was $<0.01$. The significant difference between the pre-test and post-test based on the results of Table 4 , was the sign of successful knowledge transfer through the intervention (White \& Sabarwal, 2014).

\section{Conclusion}

Fire and burns at home among children needed an attention because shown an increasing pattern. To increase the awareness and understanding of fire and burns at home setting, there is a need for educational and intervention programs. Thus, it is recommended to include some context related to fire and burns prevention and control methods and precaution in academic curriculum or in curriculum activity of students. To be effective, educational programmes need to be combined with programmes involving legislations and standards and product modifications for prevention purposes.

\section{References}

Blom, L., Klingberg, A., Laflamme, L., Wallis, L., \& Hasselberg, M. (2016). Gender differences in burns: A study from emergency centres in the Western Cape, South Africa. Burns, 42(7), 1600-1608.

Chien, C., Marriott, J. L., Ashby, K., \& Ozanne-Smith, J. (2003). Unintentional ingestion of over the counter medications in children less than 5 years old. Journal of paediatrics and child health, 39(4), 264-269.

Ghasemi, A., \& Zahediasl, S. (2012). Normality tests for statistical analysis: a guide for nonstatisticians. International journal of endocrinology and metabolism, 10(2), 486.

Hemeda, M., Maher, A., \& Mabrouk, A. (2003). Epidemiology of burns admitted to Ain Shams University burns unit, Cairo, Egypt. Burns, 29(4), 353-358.

Kulanthayan, K. C. M., Anusooyam D., Rosliza, A. M., and Pravina, J. (2016). How Safe is Your Home? Fire and Burn Injuries in Malaysia: Key Facts. 2016

MHLG Annual Report. (2016). Ministry of Housing and Local Government, Malaysia. https://www.kpkt.gov.my/resources/index/user_1/GALERI/PDF_PENERBITAN/BUKU_LAPORA N_TAHUNAN/KPKT_ANNUAL_REPORT_2016.pdf

Norton, R., Hyder, A. A., Bishai, D., \& Peden, M. (2006). Unintentional injuries. Disease control priorities in developing countries, 2, 737-753.

Olabanji, J. K., Oladele, A. O., Oginni, F. O., \& Oseni, O. G. (2007). Burn safety knowledge in adult Nigerians. Annals of Burns and Fire Disasters, 20(3), 115.

Parker, E. M., Gielen, A. C., McDonald, E. M., Shields, W. C., Trump, A. R., Koon, K. M., \& Jones, V. (2013). Fire and scald burn risks in urban communities: who is at risk and what do they believe about home safety? Health education research, 28(4), 599-611. 
Peck, M. D. (2011). Epidemiology of burns throughout the world. Part I: Distribution and risk factors. Burns, 37(7), 1087-1100. https://doi.org/10.1016/j.burns.2011.06.005

Sahril, N., Sien, Y. P., Abdul Mutalip, M. H., \& Mahadir Naidu, B. B. (2014). Home injuries among young children in Malaysia: A population based study. Clinics Mother Child Health, 11(2), 1-5.

Shi, S., Yang, H., Hui, Y., Zhou, X., Wang, T., Luo, Y., \& Shi, X. (2016). Epidemiologic characteristics, knowledge and risk factors of unintentional burns in rural children in Zunyi, Southwest China. Scientific reports, 6(1), 1-7.

Shrestha, S. R. (2006). Burn injuries in pediatric population. JNMA; journal of the Nepal Medical Association, 45(163), 300-305.

U.S Fire Administration. (n.d.). Fire Safety Trailer Curriculum. 2007. https://www.usfa.fema.gov/downloads/pdf/publications/fire_safety_trailer_curriculum.pdf

Van der Geer, J., Hanraads, J. A. J., \& Lupton, R. A. (2000). The art of writing a scientific article. J. Sci. Commun, 163(2), 51-59.

White, H., \& Sabarwal, S. (2014). Quasi-experimental design and methods: Methodological briefsimpact evaluation no. 8 (No. innpub753).

World Health Organization. Report on disability. (2011) https://doi.org/10.1136/ip.2007.018143 